Izumi, Volume 7 No 2, 2018

e-ISSN: 2502-3535, p-ISSN: 2338-249X

Tersedia online di http://ejournal.undip.ac.id/index.php/izumi

\title{
PENGGUNAAN PARTIKEL ILOKUSI NE DAN YO DALAM TUTURAN BAHASA JEPANG
}

\author{
Reny Wiyatasari \\ Universitas Diponegoro \\ reny.wiyatasari@gmail.com
}

\begin{abstract}
Abstrak
Tujuan penelitian ini adalah menjelaskan penggunaan partikel ilokusi ne dan yo, makna pragmatis yang dihasilkan dari suatu tuturan serta bagaimana pengaruh keberadaan partikel ini dalam suatu tuturan.Karena ne dan yobersifat pragmatis daripada semantik dan sifat ini hanya terjadi dalam interaksi verbal, maka artikel ini mengambil data dari sumber data, seperti drama dan cerpen berbahasa Jepang. Data dijaring menggunakan metode simak dengan teknik rekam dan catat, dan selanjutnya dianalisis menggunakan metode kontekstual. Dari hasil analisis data diketemukan bahwa : partikel nedigunakan saat: a) meminta konfirmasi atau memastikan informasi, b) meminta atau mencari kesepakatan, c) melembutkan tuturan, dan d) menekankan perasaan yang dirasakan penutur. Sedangkan partikel yo digunakan saat: a) Menegaskan pertanyaan untuk mendapatkan respon atau alasan, b) menandai bahwa informasi (pernyataan) adalah sesuatu yang baru untuk mitra wicara, c) Menekankan atau menegaskan suatu hal/tindakan yang dimaksudkan penutur dalam tuturannya, d) menandai tuturan bermakna menyemangati, e) menandai tuturan yang mengandung ungkapan perasaan penutur, dan f) menandai desakan melakukan suatu tindakan.
\end{abstract}

Kata Kunci : partikel ne dan yo,partikel ilokusi, makna pragmatis, interaksi verbal.

\begin{abstract}
(Title: Use of Illocutionary Particle in Japanese Language). The purpose of this study is to explain the use of illocutionary particles ne and yo, the pragmatic meaning generated from a speech and how the influence of the existence of each of these particles in a speech. Because ne and yo are pragmatic rather than semantic and this nature only occurs in verbal interactions, this article takes data from data sources, such as Japanese dramas and Japanese short stories. The data was collected using the observation method through recording and note-taking techniques, and then analyzed using contextual method.From the results of data analysis it was found that ne particles are used when a) request confirmation or ensure information, b) request or seek agreement, c) soften speech, and d) marking the feelings felt by the speaker. While yo particles are used when : a) confirming the question to get a response or reason, b) marking that information (statement) is something new for the listerner, c) emphasizing or affirming a matter/action intended by the speaker in his speech, d) marking speech means encouraging, e) marking utterances that contain expressions of the feeling of the speaker, and f) marking the urge to take action.
\end{abstract}

Keywords : ne and yo particles, illocutionary particles, pragmatic meanings, verbal interactions 
Izumi, Volume 7 No 2, 2018

e-ISSN: 2502-3535, p-ISSN: 2338-249X

Tersedia online di http://ejournal.undip.ac.id/index.php/izumi

\section{PENDAHULUAN}

Hubungan antara suatu tuturan dengan konteks serta situasi pemakaiannya menjadi kajian utama pragmatik. Melalui hubungan tersebut akan diketahui bagaimana penggunaan bahasa dalam suatu komunikasi. Tuturanilokusioner merupakan salah satu tindak tutur yang menarik untuk ditelaah karena petuturan ilokusioner mengandung daya ilokusi (illocutionary force). Melalui daya ilokusi tuturan tersebut akan dihasilkanmakna yang mengandung efek yang disebutsebagai makna ilokusioner(illocutionary meaning). Daya ilokusi ini membantuseorang penutur agar bisa menyampaikan amanat/makna tuturannyakepada mitra wicaranya. Dalam bahasa Jepang terdapat partikel akhir yang memiliki fungsi yang hampir sama dengan penanda fatis dalam bahasa Indonesia dan lebih banyak dijumpai dalam bahasa lisan atau percakapan.Seperti yang dinyatakan oleh Hideki (2011) bahwa partikel yo dan ne merupakan penanda linguistik yang khas karena kedua partikel bersifat pragmatis daripada semantik. Sifat pragmatis tersebut hanya terjadi dalam interaksi verbal.

Partikel akhir ini, bersaman dengan tinggi-rendahnya nada suara, membantu menyampaikan nuansa emosional penutur, dan seringkali tanpa benar-benar mengubah makna eksplisit dari kalimat. Sebagai contoh onegaishimasu, onegaishimasune, dan onegaishimasuyo yang digunakan untuk mengungkapkan permintaan pada intinya memiliki makna yang sama, namun menjadi lebih lunak atau ditekankan melalui penambahan partikel akhir (Naoko, 1991 : 128)

Berkaitan dengan partikel akhir ini, Hideki (2011 : 159) menyatakan sebagai berikut : Within speech act theory the particles ne, yo and yone may be thought of as illocutionary particles (cf. Goddard 1998: 169) in the sense that they have the force to direct the addressee as to how to understand the speaker's pragmatic, and particularly interactional intentions. To put it another way, in order to become competent in the use of the particles, one has to understand their pragmatic effect. (Hideki, 2011: 62).

Sesuai dengan teori tindak tutur, partikel akhir, seperti yo dan neyang disebut sebagai partikel ilokusidapat mengarahkan mitra wicara memahami makna pragmatis, terutama maksud penutur dalam suatu interaksi atau komunikasi. Tambahan lagi, dalam suatu komunikasi, partikel akhir juga memenuhi fungsi sebagai illocutionary modulation (modulasi ilokusi), yaitu tanda tambahan pada klausa yang menghubungkan klausa yang ditandai dengan wacana dan situasi tutur atau tanda tambahan pada klausa yang berfungsi untuk melemahkan atau menguatkan daya ilokusi. Dengan demikian, agar seseorang mampu menggunakan partikel akhir dengan baik, ia harus memahami efek pragmatis yang ditimbulkan oleh setiap partikel.

Salah satu penelitian tentang partikel akhir adalah yang ditulis oleh Nazaya Zulaikha (Universitas Dharma Agung) dan Nandang Rahmat (Universitas Padjajaran) berjudul : Analisis Partikel Pemerkah Emotif Bahasa Jepang Satu Kajian Pragmatik (dalam Jurnal Kajian Lingusitik, Februari 2013). Dalam penelitian tersebut dibahas tentang partikel yang terdapat dalam kalimat percakapan yang membawa makna emotif yang dituturkan oleh penutur, baik penutur wanita maupun pria, dalam komik "Gals!" karya Mihona Fujii jilid 1, 2, dan 3.Partikel-partikel yang dibahas dalam kaitannya dengan makna emotif yang ditimbulkan dalampercakapan, di antaranya : ka, sa, tteba, mon, ne, na, noni, dan sebagainya. Berkaitan dengan partikel ne dan yo, kedua penulis menjelaskan bahwa penggunaan yo adalah untuk menunjukkan emosi kekhwatiran dan ne digunakan untuk menunjukkan makna emotif senang.Berbeda dengan penelitian sebelumnya, penelitian ini lebih 
banyak menemukan penggunaan ne dan yo dikarenakan sumber data yang digunakan pun juga bervariasi. Karena itu, penjelasan tentang penggunaan dan makna pragmatis partikel ne dan yodalam artikel ini lebih lengkap, sehingga diyakini akan memberi pemahaman yang lebih dalam terhadap pembaca tentang kedua partikel ini.

Tujuan artikel ini, penulis adalah membahas penggunaan partikel akhir, khususnya ne dan yo, dan karena keduanya sering muncul dalam percakapan verbal, maka data diambil dari sumber data, seperti drama dan cerpen berbahasa Jepang. Di samping itu, melalui artikel ini akan dibahas juga makna pragmatis atau ilokusi yang dihasilkanserta bagaimana pengaruh keberadaan partikel ne atau yo dalam suatu tuturan.Diharapkan melalui artikel ini akan semakin menambah pengetahuan dan pemahaman tentang peran dan ketepatan penggunaan partikel akhir bahasa Jepang dalam suatu tuturan.

\section{METODE PENELITIAN}

Karena artikel ini hanya menjelaskan setiap data berdasarkan fenomena kebahasaan yang ditemukan di sumber data berbahasa Jepang, maka penelitian ini termasuk dalam deskriptif kualitatif. Data dijaring menggunakan metode simak dengan teknik rekam dan catat. Karena artikel ini menggunakan pendekatan pragmatik, maka analisis data dilakukan berdasarkan faktor-faktor ektralinguistik yang menaungi dan menjadi latar munculnya penggunaan ne atau yo, tanpa mengesampingkan faktor intralingusitik. Dengan demikian metode analisis data yang paling tepat untuk dipilih dan digunakan adalah metode kontekstual menurut Rahardi (2005).

\section{PEMBAHASAN}

Pada bagian pembahasan berikut akan ditampilkan data berwujud tuturan berpartikel akhir ne dan yo. Data diambil dari beberapa sumber data, seperti drama dan cerpen berbahasa Jepang.

\subsection{Partikel $N e$.}

Dari sekian data berpartikel ne diketahui bahwa penggunaannya paling sering untuk meminta konfirmasi/kepastian atau memastikan informasi dan untuk meminta atau mencari kesepakatan (persetujuan). Selain itu, ne juga digunakan oleh penutur pada saat melembutkan tuturannya serta mengungkapkan emosi atau perasaan penutur.

\section{a. Meminta konfirmasi atau} memastikan informasi.

Makna ilokusioner memastikan termasuk dalam tindak tutur asertif. Dalam kaitannya dengan ilokusi memastikan, penggunaan partikel ne berfungsi untuk meminta konfirmasi (mengkonfirmasi informasi) dan mencari kesepakatan (persetujuan), .

Sebagai sampel, data diambil dari salah satu drama berbahasa Jepang sebagai berikut :

Sanoo bertemu dengan Asumi, siswi baru di sekolah Aerospace tempat Sanno mengajar. Sanoo meyakini bahwa Asumi yang saat itu memanggil dirinya "Sanno Sensei" adalah putri teman dekatnya .

$$
\begin{aligned}
& \text { アスミ : サンノ先生。 } \\
& \text { サンノ：カモガワアスミ君だ } \\
& \text { ね? } \\
& \text { アスミ：あっ、もう名前、覚え } \\
& \text { てくださったんですか。 } \\
& \text { (Futasuno Supika, } \\
& \text { 2009/1/00: 07: 29) }
\end{aligned}
$$

Sanno menandai pertanyaannya dengan ne karena ia bermaksud mengkonfimasi keakuratan proposisinya. Saat bertemu dengan Asumi dan Asumi memanggilnya, 
Sanno bermaksud mengkonfirmasi keyakinan yang dimilikinya tentang jati diri Asumi kalau memang benar dia putri teman dekat Sanno. Bereaksi terhadap kekuatan ne, Asumi mengatakan'あっ、もう名前、覚え てくださったんですか (artinya: Ah, Bapak ingat nama saya). Asumi menggunakan bentuk jujuhyougen ragam hormat untuk mengungkapkan perasaan terimakasih karena di luar dugaan Asumi, Sanno sudah mengingat namanya, meskipun ia adalah siswi baru di sekolah tersebut. Ketiadaan ne tidak dimungkinkana dalam konteks di atas karena dengan demikian ilokusi memastikan informasi tidak akan tercapai. Penggunaan ne konteks ini sesuai dengan teori yang menyatakan bahwa ne berfungsi untuk meminta konfirmasi (seperti saat mengkonfirmasi keakuratan suatu pernyataan).

\section{b. Meminta atau mencari kesepakatan (persetujuan).}

Konteks data berikut adalah seorang karyawan di toko milik Satoshi mengungkapkan keherannya terhadap Satoshi yang sama sekali tidak menyadari kalau Karin yang beberapa hari sudah menginap di toko Satoshi sebenarnya adalah teman masa kecil Satoshi.

$$
\begin{aligned}
& \text { 店員：やあ、おどろきですね。 } \\
& \text { びっくりです。. } \\
& \text { サトシ：僕も驚いたんですよ } \\
& \text { 店員 : 違いますよ。幼馴染み } \\
& \text { だとここまで気づくな } \\
& \text { かった店長に僕の驚い } \\
& \text { たんですよ。 }
\end{aligned}
$$

(Sonotokiwa Kareni
Yoroshiku, 2007/ 00 :

$36: 21)$

Sesuai dengan penggunaan ne yang berfungsi untuk mencari/meminta kesepakatan, maka tuturan “やあ、お どろきですね” (artinya：Yah, ini luar biasa) yang mengandungilokusi rasa heran (tindak tutur ekspresif) bertujuan untuk meminta persetujuan mitra wicara (Satoshi) tentang keheranan penutur atas apa yang dialamioleh Satoshi. Namun ternyata Satoshi tidak menangkap maksud yang ingin disampaikan penutur. Karena itu, pada giliran berikutnya, penutur kembali menegaskan tuturannya dengan mengatakan 違います L'Bukan itu maksud saya'dengan menambahkan partikel yountuk menegaskan bahwa maksud penutur berbeda dengan yang dipikirkan Satoshi. Apabila tanpa ne, maka ilokusiyang dihasilkan akan berbeda. Karena kalau demikian, rasa heran hanya ditujukan penutur untuk dirinya sendiri.

\section{c. Melembutkan tuturan.}

Seorang murid (tokoh utama cerita) bersama dengan Jim dan Ibu guru sedang bercakap-cakap di ruang guru. Setelah Jim memberi maaf atas kesalahan yang dilakukan oleh tokoh utama karena telahmencuri crayon warna milik Jim, si tokoh utama merasa lega.

$$
\begin{array}{ll}
\text { 先生 } & \text { : 昨日の葡萄は美味しか } \\
& \text { ったの。 } \\
\text { 学生 } & : \text { ええ。 } \\
\text { 先生 } & \text { :そんなら又あげましょ } \\
& \text { うね。 }
\end{array}
$$

(Hitofusano Budoo, Arishima Takeo) 
Izumi, Volume 7 No 2, 2018

e-ISSN: 2502-3535, p-ISSN: 2338-249X

Tersedia online di http://ejournal.undip.ac.id/index.php/izumi

Setelah mendengar jawaban muridnya (tokoh utama) yang mengiyakan pertanyaannya, “昨日の 葡萄は美味しかったの” Ibu guru bertanya dengan maksud menawarkan buah anggur lagi dengan mengatakan そんなら又あげましょうね (artinya : Kalau begitu, Aku akan berikan lagi anggur untukmu, ya), dan pada titik ini guru menggunakan ne. Percakapan di atas dilatari oleh situasi yang dialami oleh muridnya kedapatan mengambil crayon milik temannya dan hal tersebut membuat si murid merasa malu. Ibu Guru melembutkan tuturannya dengan menggunakan ne dengan maksud memperlakukan siswanya lebih dekat supaya muridnya dengan mudah atau tanpa merasa malu mau menerima tawarannya tersebut. Dari pihak mitra tutur, mungkin dia justru senang dengan penggunaan $n e$ karena merasa diperlakukan lebih $\mathrm{akrab} /$ dekat oleh gurunya. Bisa saja Ibu guru tidak menggunakan ne, namun bila demikian penutur mungkin saja merasa tidak nyaman karena terkesan tawarannya tersebut tidak disertai harapan yang kuat agar mitra wicaranya mau menerimanya.

Sementara itu, penggunaan ne pada data berikut adalah untuk melembutkan tuturan bermakna ajakan untuk bertemu lagi yang dinyatakan oleh Miyuki kepada Yuuki yang akan pulang ke Jepang setelah beberapa waktu lamanya tinggal bersama-sama di kamp penampungan di Perth, Australia.

$$
\begin{aligned}
& \text { ミュキ:また会おうね。 } \\
& \text { ユウキ:また、じやあ日本で。 } \\
& \text { (Yuuki, 2006/ 00.14.31) }
\end{aligned}
$$

Penggunaan ne seperti tuturan Miyuki di atas sudah sangat umum atau sering dijumpai dalam konteks hubungan pertemanan dan lebih banyak digunakan oleh wanita. Meskipun demikian, tanpa nepun juga lazim digunakan dan pada umumnya oleh kaum laki-laki, dan itu tidak tidak akan mengubah makna. Pada tuturan di atas ajakan akan terdengar lebih lembut dengan penggunaan $n e$, dan respon Yuki pada giliran berikutnya menandakan

penerimaan/persetujuanYuki atas ajakan tersebut.

Penggunaan ne lainnya diketemukan dalam ungkapan permintaan yang dinyatakan oleh seorang dokter kepada pasiennya, yaitu Yuuki, saat Yuuki menjalani tes MRI.

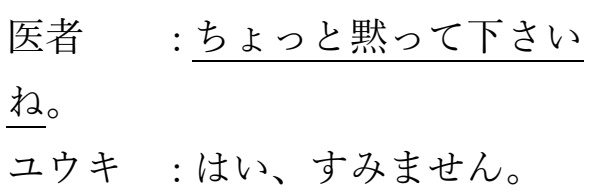

(Yuuki, 2006/00:20:16)

Dokter menggunakan ne pada tuturan permintaannya dengan harapan agar Yuuki mematuhi permintaanya untuk lebih tenang dan fokus selama menjalani pemerikaan MRI. Dengan menggunakan ne, tuturan bermakna permintaan yang dinyatakan penutur terdengar lebih halus/lembut. Dalam konteks hubungan dokter-pasien di rumah sakit, penggunaan neoleh dokter menandakan kesopanan yang hendak ditunjukkan oleh dokter terhadap pasien yang diposisikan sebagai tamu rumah sakit.

Sesuai dengan fungsi ne, yaitu sebagai pencari penerimaan, maka penggunaan ne pada tuturan permintaan di atas dimaksudkan agar mitra tutur menerima atau mematuhi penutur. Sesuai konteks di atas respon Yuuki dengan mengucapkan “はい、

すみません” menandakan penerimaan sekaligus permintaan maaf Yuki. Dalam konteks di atas, dimungkinkan untuk peniadaan ne, 
namun tuturan permintaan dokter akan terdengar lebih tegas atau keras.

Selanjutnya, ne juga digunakan untuk melembutkan ungkapan permintaan maaf dalam konteks hubungan suami-istri, seperti berikut.

$$
\begin{aligned}
& \text { タクミ：ごめんね。君を幸せに } \\
& \text { してあげたかった。僕 } \\
& \text { はミオを幸せにできな } \\
& \text { かった。ごめんね } \\
& \text { ミオ：何言ってんのよ、よく } \\
& \text { 似た親子だな。幸せだ } \\
& \text { ったよ、私はずっと幸 } \\
& \text { せだった。あなたを好 } \\
& \text { きになってから、ずっ } \\
& \text { と。 } \\
& \text { (Ima, Aini Yukimasu, } \\
& \text { 2004/01: 34: 18) }
\end{aligned}
$$

Takumi yang merasa bersalah kepada istrinya, karena selama Mio hidup, Takumi merasa tidakpernah bisa membahagiakan Mio. Pada ekpresi permintaan maaf “ごめん ね "inilah, Takumi menggunakan neuntuk melembutkan tuturannya.

\section{d. Menandai tuturan mengungkapkan emosi atau perasaan penutur.}

Tuturan yang mengungkapkan perasaan penutur adalah saat Takumi bercerita kepada temannya seorang dokter tentang istrinya yang sudah meninggal, namun di musim hujan istrinya, Mio, kembali datang sesuai dengan janjinya. Meskipun cerita Takumi terdengar tidak masuk akal, namun dokter mencoba memahami perasaan Takumi.

$$
\begin{gathered}
\text { タミ : 信じてくれなくていいん } \\
\text { です。ごめんなさい。 } \\
\text { 忘れてください。 }
\end{gathered}
$$

医者：困りましたね。

タクミ：すみません。

医者：でも、もし君の言った

ことは本当だとして。

(Ima, Aini Yukimasu, 2004/00: 54:00).

Saat mendengar cerita Takumi, dokter yang memahami perasaan Takumi menyatakan “困りましたね” Maksud penutur melalui tuturan ini adalah : Saya bingung, apalagi Anda juga pasti mengalami kebingungan, menunjukkan rasa empati penutur kepada Takumi, dan di akhir tuturan inilah dokter menggunakan neuntuk melembutkanpernyataannya. Dalam konteks demikian, ne harus ada, karena tanpa ne tuturan dokter terkesan tegas atau keras, sehingga tidak sesuai untuk konteks situasi pada data di atas. Dengan adanya ne, tergambar bahwa di sini penutur memposisikan dirinya sebagai orang yang bisa merasa empati atas apa yang dialami oleh mitra wicaranya.

Pada data berikut, Satoshi mengajak Karin mengunjungi Ayahnya. Ayah Satoshi yang sudah lama tidak bertemu Karin merasa senang akhirnya bisa berjumpa kembali dengan Karin.

$$
\begin{aligned}
& \text { お父さん：カリンちゃん。 } \\
& \text { カリン : ご無沙汰してわ。 } \\
& \text { お父さん：よく来てくれたね。 }
\end{aligned}
$$




じゃあ、どうぞ、どう
ぞ。 (SonotokiwaKareni
Yoroshiku, 2007/
00:45: 50)
Perasaan senang sekaligus terima
kasih atas kedatangan mitranya tersirat
dalam ungkapan “よく来てくれたね”
(artinya : Saya senang kamu datang),
dan pada ungkapan ini, penutur
menggunakan neuntuk menekankan
perasaannya.Meskipun makna tuturan
di atas tidak mengalami perubahan
bila tanpa menyertakan ne, namun
terasa ada yang kurang karena dengan
ne membuat ungkapan di atas
terdengar lebih lembut atau manis,
sehingga umumnya ne selalu
disertakan dalam konteks bahasa
percakapan.

\subsection{Partikel Yo}

Dari sekian data yang mengandung partikel yo diketahui bahwa yomemiliki enam penggunaan seperti berikut.

\section{a. Menegaskan pertanyaan untuk mendapatkan respon/alasan}

Sesuai dengan fungsinya, yo digunakan untuk menegaskan pertanyaan dengan maksud mendapatkan respon dari mitra wicara, dan tanggapan mitra wicara didasarkan pada dugaan mengapa penutur mengajukan pertanyaan tersebut. Data berikut adalah salah satu contohnya.

$$
\begin{array}{ll}
\text { サトシ } & : \text { ごうして言ってくれな } \\
\text { カリン } & \text { かったんだよ。 } \\
& \text { :っちだって意地にな } \\
& \text { っちゃうわよ、ぜんぜん } \\
& \text { 思い出してくれないんだ } \\
& \text { もん、サトシ。 }
\end{array}
$$

(Sonotokiwa Kareni

Yoroshiku,2007/ 00: 33: 44)
Yo muncul di akhir tuturan berbentuk pertanyaan “どうして言っ てくれなかったんだよ” (artinya : Kenapa sih kamu ga bilang) yang ditujukan Satoshi kepada Karin. Satoshi yang merasa gusar menggunakan yo untuk mendapatkan penjelasan dari Karin kenapa sejak awal kedatangan Karin ke tokonya, Karin tidak langsung mengatakan bahwa dirinya adalah teman kecil Satoshi, sehingga ia bertanya dan berharap Karin memberikan alasan. Meskipun tanpa yo tidak akan mengubah makna tuturan, namun hal tersebut akan mengurangi kekuatan dari harapan Satoshi untuk mendapatkan respon dari Karin.Alasan yang dinyatakan Karin pada giliran berikutnya bisa disimpulkan sebagai reaksi Karin atas kekuatan yo.

\section{b. Menandai bahwa informasi (pernyataan) adalah sesuatu yang baru untuk mitra wicara.}

Berikut adalah salah satu contoh data yang di dalamnya menggunakan partikel yo yang digunakan oleh Ayah Satoshi saat berbicara dengan Satoshi tentang penyakit Karin yang selama ini belum diketahui oleh Satoshi. Ayah Satoshi memberitahukan kepada Satoshi bahwa obat yang diminum oleh Karin bukan obat tidur, namun obat yang justru menahan agar Karin tidak tertidur karena kalau sampai tertidur menyebabkan nyawa Karin bisa saja tidak tertolong. Ayah menggunakan yo pada tuturannya karena informasi yang dia nyatakan adalah baru bagi Satoshi. Keberadaan yo dalam konteks ini adalah penting, karena bila tanpa yo, maka ilokusi memberitahu tidak akan tersampaikan.

$$
\begin{array}{r}
\text { お父さん:それカリンさんが飲ん } \\
\text { でたくすりだろう？ }
\end{array}
$$


Izumi, Volume 7 No 2, 2018

e-ISSN: 2502-3535, p-ISSN: 2338-249X

Tersedia online di http://ejournal.undip.ac.id/index.php/izumi

サトシ：お父さん、不眠症の薬

$$
\text { でしょう。 }
$$

お父さん：いや。眠れないするよ

うにための薬で、カリ

ンさんがもう時間がな

い。カリンちゃん、病

気だったんだよ。

サトシ : 病気?

(Sonotokiwa Kareni Yoroshiku, 2007/01:09:01)

c. Menekankan atau menegaskan suatu hal/tindakan yang dimaksudkan penutur dalam tuturannya.

Pada percakapan berikut, yo digunakan untuk menekankan niat yang akan dilakukan oleh Yosuke demi mendapatkan maaf dari Akane.Yosuke berjanji akan selalu mengantar dan menjemput Akane, serta akan menemani Akane kapanpun dan kemanapun dia pergi. Pada titik ini, Yosuke menggunakan yo sebagai penekanan atas tindakan yang hendak dilakukannyademi Akane.

アカネ：聞きたくない。

ヨウスケ：どうすれば 許してく

れる？何でもするから。

アカネ：だったら、私の前に

二度と現れないで。

ヨウスケ：毎日 送り迎えするよ。

朝でも夜中でも、どこ

でも行くよ。もう危険

なめにあわないよう

に、俺が守るから。

アカネ : 行こう。
ヨウスケ：俺、あきらめないから、 あんたが許してくれる まで。

(Hoteria, 2009/00: 08: 50)

Data lainnya adalah percakapan antara Asumi dengan Fuchuya di halaman depan sekolah. Asumi yang melihat Fuchuya menyapa Asumi dengan memgatakan "何にしょぼく れてんだよ” (artinya : Ada apa, kok kelihatannya lesu).

$$
\begin{array}{ll}
\text { フチュウヤ } & \text { : 何にしょぼくれ } \\
& \text { てんだよ。 } \\
\text { アスミ } & \text { : 待っててくれた } \\
& \text { の? } \\
\text { フチュウヤ } & \text { : ちげーよ、たま } \\
& \text { たまだよ。 } \\
\text { アスミ } & \text { : 有難う。 }
\end{array}
$$

(Futatsuno Supika, 2009/ 00: 03 05)

Pada tuturan di atas, Fuchuya menggunakan yo di akhir kata “ちげ ーよ” (sama dengan ちがうよ) dan “たまたまだよ” (arinya : kebetulan) untuk menekankan atau menegaskan bahwa keberadaannya di halaman sekolah bukan sengaja dilakukan untuk menunggu Asumi, seperti yang dipikirkan Asumi, namun memang kebetulan saja ia berada di situ dan melihat Asumi.

d. Menandai tuturan bermakna menyemangati

Berikut adalah percakapanantara Yuji, Karin, dan Satoshi, saat mereka bertiga masih kecil. Yuji memiliki hobi melukis dan bercita-cita suatu saat bisa menjadi seorang pelukis terkenal. Karena kalau dia terkenal ia yakin bahwa Ibu kandung yang selama 
ini tidak diketahui keberadaannya akan kembali menemui dirinya.

ユウジ: 僕、大人になったら画

家になれるかな。

カリン: なれるよ。あたしが保

サトシ: 僕もそう思うよ。。

ユウジ: 有名な画家になったら、 お母さん帰ってきてくれ

ると思うんだ。

(Sonotokiwa Kareni

Yoroshiku, 2007/00:34: 53)

Baik Karin maupun Satoshi menggunakan yo di akhir tuturan mereka dengan maksud yang sebenarnya adalah untuk menyemangati Yuji. Apabila yo dihilangkan, maka itu akan mempengaruhi makna tuturan dan ilokusi di atas juga tidak akan tersampaikan.

e. Menandaituturan

yang mengandung ungkapan perasaan penutur.

Di samping menandai ungkapan kekesalan, penggunaan yo lainnya adalah menandai ungkapan perasaan, seperti omelan, keluhan, kecaman, maupun kritikan (Naoko, 1991 : 131Salah satunya, seperti yodi akhir tuturan Karin berikut.

サトシ：どうして言ってくれなか

ったんだよ。

カリン：こっちだって意地になっ

ちゃうわよ、ぜんぜん思い出して

くれないんだもん、サ

トシ。

(Sonotokiwa Kareni Yoroshiku, 2007/

00: 33: 44)
Tuturan Karin“こっちだって意地

になっちゃうわよ” (artinya : Abis, kamu juga keras kepala, sih) di atas, di samping berisi alasan atas pertanyaan Satoshi, sekaligus juga menggambarkan ungkapan kekesalan Karin terhadap sikap Satoshi di saat kedatangan Karin pertama kalinya ke toko Satoshi. Satoshi sama sekali tidak mengenali Karin, bahkan Satoshi berpikir bahwa Karin datang karena berminat untuk melamar pekerjaan sebagai karyawan di tokonya.

f. Menandai desakan untuk melakukan suatu tindakan

Berikut adalah percakapan antara Asumi dan Omi di sekolah saat keduanya mengalami kesulitan mengerjakan soal pelajaran.

$$
\begin{aligned}
& \text { アスミ：あ、あの子同じクラス } \\
& \text { じゃん。聞いてみよう } \\
& \text { L。 } \\
& \text { オミ：やめときな。何かゲイ } \\
& \text { の娘で感じ悪いんだっ } \\
& \text { て。まあ入試の成績は } \\
& 2 \text { 位だったらしいけど } \\
& \text { ね } \\
& \text { アスミ：へえ、すっごーい } \\
& \text { オミ：どうせ、親のコネで、 } \\
& \text { 点数水増ししてもらっ } \\
& \text { たんじゃないの。コネ } \\
& \text { とか使ったりするやつ、 } \\
& \text { 許されなくない? }
\end{aligned}
$$

(Futatsuno Supika, 2009/ 00: 08: 10)

Tuturan Asumi “あ、あの子同じ クラスじゃん。聞いてみよう L"(artinya : Ah, anak itu, ternyata sekelas dengan kita. Ayo, kita tanya ke dia saja) ditujukan kepada Omi tidak hanya sekedar bermakna ajakan, 
Izumi, Volume 7 No 2, 2018

e-ISSN: 2502-3535, p-ISSN: 2338-249X

Tersedia online di http://ejournal.undip.ac.id/index.php/izumi

namun juga mendesak Omi agar bersama-sama bertanya tentang soal pelajaran yang tidak mereka pahami kepada salah seorang siswa yang pintar yang kebetulan pada saat itu terlihat berjalan tidak jauh dari tempat keduanya berbicara. Penggunaan yo dalam konteks ini adalah keharusan, karena apabila tidak, maka siapa yang diajak oleh Asumi menjadi tidak jelas, bahkan kalau tanpa yo, bisa saja ajakan itu bukan ditujukan kepada Omi, namun kepada orang selain Omi. Atau, bisa saja tindakan bertanya dilakukan oleh Asumi sendiri.

\section{SIMPULAN}

Partikel ne dan yoternyata tidak hanya sekedar penanda linguistik yang terbatas penggunaannya hanya untuk menambah makna, namun juga mempunyai peranan penting karena membantu kelancaran komunikasi seseorang, terutama untuk menyampaikan ilokusi-ilokusi tertentu serta bisa membangun kedekatan di antara partisipan yang terlibat dalam suatu situasi tutur. Dalam situasi informal atau percakapan, penggunaan ne atau yo hampir selalu ada. Karena itu, seorang pembelajar bahasa Jepang perlu memahami dengan tepatpenggunaan serta makna pragmatis kedua partikel ini. Melalui keduanya, penutur bisa menyampaikan berbagai maksud, di antaranya saat meminta konfirmasi, meminta persetujuan, memberitahu suatu informasi yang baru, mendesak mitranya untuk melakukansuatu tindakan, dan sebagainya.

\section{DAFTAR PUSTAKA}

Chino, Naoko. (2001). All About Particles. A Handbook of Japanese
Function Words. Tokyo. Kodansha International Ltd.

Hideki, Saigo. (2011). The Japanese Sentence-Final Particles in Talkin- Interaction. Amsterdam/ Philadelphia. John Benjamins Publishing Company.

Leech, Geoffrey. (1993). Prinsip-Prinsip Pragmatik. Jakarta: Universitas Indonesia.

Mahsun. (2005). Metode Penelitian Bahasa. Jakarta. PT. Raja Grafindo Persada

Narrog, Heiko. (2009). Modality in Japanese. The layered structure of the clause and hierarchies of functional categories. Amsterdam/ Philadelphia. John Benjamins Publishing Company.

Pujo Purnomo, Antonius R. (2010). Antologi Kesusastraan Anak Jepang. Surabaya. Eramedia Publiser.

Soedaryanto. (2001). Metode dan Aneka Teknik Analisis Bahasa. Yogyakarta: Duta Wacana University Press.

Rujukan dari internet

http://repository.usu.ac.id/bitstream/handle 123456789/45124/Nazaya\%20Zulaikha.p df? sequence $=1$ (diunduh 29, Agustus 2018) 